\title{
No evidence of harmful effects of steroids in severe exacerbations of COPD associated with influenza
}

\author{
Severin Studer ${ }^{1} \cdot$ Frank Rassouli $^{2} \cdot$ Frederike Waldeck $^{3} \cdot$ Martin H. Brutsche $^{2} \cdot$ Florent Baty $^{2} \cdot$ Werner C. Albrich $^{3}$ (D)
}

Received: 12 July 2021 / Accepted: 10 December 2021 / Published online: 29 January 2022

(c) The Author(s), under exclusive licence to Springer-Verlag GmbH Germany 2021

\begin{abstract}
Purpose COPD has large impact on patient morbidity and mortality worldwide. Acute exacerbations (AECOPD) are mostly triggered by respiratory infections including influenza. While corticosteroids are strongly recommended in AECOPD, they are potentially harmful during influenza. We aimed to evaluate if steroid treatment for AECOPD due to influenza may worsen outcomes.

Methods A retrospective analysis of a Swiss nation-wide hospitalization database was conducted identifying all AECOPD hospitalisations between 2012 and 2017. In separate analyses, outcomes concerning length-of-stay (LOS), in-hospital mortality, rehospitalisation rate, empyema and aspergillosis were compared between AECOPD during and outside influenza season; AECOPD with and without laboratory-confirmed influenza; and AECOPD plus pneumonia with and without laboratoryconfirmed influenza.

Results Patients hospitalized for AECOPD during influenza season showed shorter LOS (11.3 vs. 11.6 day, $p<0.001)$ but higher rehospitalisation rates (33 vs $31 \%, p<0.001$ ) compared to those hospitalized outside influenza season. Patients with confirmed influenza infection had lower in-hospital mortality $(3.3$ vs. $5.5 \%, p=0.010)$ and rehospitalisation rates (29 vs. $37 \%, p<0.001)$ than those without confirmed influenza.

Conclusion Using different indicators for influenza as the likely cause of AECOPD, we found no consistent evidence of worse outcomes of AECOPD due to influenza for hospitalized patients. Assuming that most of these patients received corticosteroids, as it is accepted standard of care in Switzerland, this study gives no evidence to change the current practice of using corticosteroids for hospitalized AECOPD independent of the influenza status.
\end{abstract}

Keywords COPD $\cdot$ Influenza $\cdot$ AECOPD $\cdot$ Corticosteroids

\section{Background}

Chronic obstructive pulmonary disease (COPD) with its still growing number of patients and high mortality ranks among the top five causes of death worldwide [1-3]. Due to its chronicity, COPD patients often need lifelong therapy. Especially, acute exacerbations of COPD (AECOPD) make

Werner C. Albrich

werner.albrich@kssg.ch

1 Department of Internal Medicine, Cantonal Hospital St. Gallen, St. Gallen, Switzerland

2 Lung Center, Cantonal Hospital St. Gallen, St. Gallen, Switzerland

3 Division of Infectious Diseases and Hospital Epidemiology, Cantonal Hospital St. Gallen, St. Gallen, Switzerland the disease accountable for a high burden for the health care system and economy $[4,5]$.

AECOPD are estimated to be caused in $75 \%$ of cases by respiratory infections, of which about one-third are each bacterial, viral or bacterial/viral coinfections [6]. Among the viral aetiologies, the influenza virus, which is treatable, is estimated to trigger about 5-10\% of AECOPD [7, 8]. Therefore, testing for influenza is recommended for all patients with AECOPD and symptoms suspicious for influenza, especially during influenza season [9, 10]. If influenza is detected, it is usually considered as the likely trigger of an AECOPD.

Basic pillars for the treatment of patients with AECOPD are short-acting bronchodilators, treatment of the underlying infection, sufficient oxygenation and systemic corticosteroids [11]. In a systematic Cochrane review, the latter were shown to result in better outcomes for lung function, 
symptoms, length of hospital stay (LOS) and treatment failure in AECOPD compared to placebo [12].

With accumulating data since the 2009 Swine flu pandemic, corticosteroids have fallen out of favor in the management of influenza as they were associated with an increased mortality [13]. Controversy still exists about the use of corticosteroids in patients with pneumonia without COPD [14-17]. The German S3 guidelines recommend against systemic corticosteroids in patients with severe influenza pneumonia who do not suffer from COPD [18]. However, the same guidelines state that COPD patients with increasing obstruction in the context of pneumonia should receive systemic corticosteroids as adjunctive therapy [18]. One study suggested that asthmatics had a less severe outcome than non-asthmatics from Influenza A/H1N1 2009 possibly due to corticosteroids used for maintenance therapy [19].

In short, the strong recommendation for the use of corticosteroids for AECOPD and the current recommendation of not using corticosteroids in influenza still represent a management dilemma for the treatment of exacerbations of COPD with confirmed or suspected influenza. Given the lack of RCTs, we performed this retrospective analysis to shed more light into this surprisingly little investigated topic.

\section{Methods}

As data source, we used the "Swiss Hospital Database" provided by the Swiss Federal Statistical Office (FSO), which is a nation-wide dataset and belongs to the FSO [20]. This database provides a diagnosis list including one main diagnosis plus up to 50 additional diagnoses following the ICD-10 system for each hospitalization in Switzerland since 1998. It therefore provides an accurate representation of the (hospitalized) Swiss population and has previously been used for similar analyses [21]. The diagnoses are listed as provided by the hospitals which usually engage dedicated coding experts who extract information from available medical records.

In this database, provided by the Swiss FSO, the patient information is fully anonymized. Thereby, and in accordance with relevant guidelines and regulations, no written informed consent is necessary for patients, since they are unidentifiable due to the anonymization. As a consequence, the protocol did not have to be approved by an institutional committee. The database contains very limited epidemiologic information and largely lacks clinical details such as severity of disease, smoking history or vaccination status.

\section{Inclusion/exclusion criteria}

We included data from 2012 to 2017, as professional and consistent coding of diseases started only in 2012, when coded diagnoses became revenue-relevant for hospitals and assurers. The only additional exclusion criterion was patient age of $<40$ years, as COPD can formally hardly be diagnosed below that limit.

\section{Analyses and statistical methods}

After screening the about 8 million database entries between 2012 and 2017 with the statistical program R, we conducted three separate analyses working with ICD-10-coded diagnoses such as AECOPD, influenza, pneumonia and their possible combinations. Relevant codes and code-combinations to build the comparison groups for the three analyses were elaborated together with the coding department of the Cantonal Hospital St. Gallen. As the coding order results from the relative weighing of each diagnosis in hospitalisations with several occurring medical problems, all hospitalization-related diagnoses were screened. For each separate analysis conducted, differences between groups concerning LOS, in-hospital mortality and risk of re-hospitalization for AECOPD within the study period (2012-2017) were assessed. In addition, we assessed the risk of aspergillosis in each group and, for analysis 3 only, the occurrence of empyema.

Analysis 1 compared outcomes of patients with AECOPD during vs. outside the influenza epidemic period. Influenza epidemic period was defined using information provided by the Swiss general practitioners-led surveillance tool "Sentinella", which defines for each influenza epidemic the calendar weeks during which a threshold of a predefined number of consultations per 100,000 inhabitants with suspected influenza is surpassed, thereby defining the national epidemic period (www.sentinella.ch) [22]. As the Swiss Hospital Database classifies data in a month-based system, influenza epidemic weeks of the "Sentinella" system were translated into influenza epidemic months. Each month containing at least 1 day of an influenza epidemic week was declared as influenza epidemic month.

Analysis 2 compared AECOPD with laboratory proof of concomitant influenza infection with AECOPD without proof of concomitant influenza infection, i.e., influenza polymerase chain reaction (PCR) was either negative or not conducted. Due to fundamental difference in management, all patients with pneumonia were preliminary excluded from analyses 1 and 2.

Analysis 3 compared patients with COPD with and without concomitant laboratory-confirmed influenza infection, among patients with an additional diagnosis of pneumonia.

The exact ICD-10 codes used to construct the comparison groups for analysis 1 to 3 are available in the supplementary material.

Differences in terms of LOS were tested using Wilcoxon rank sum tests. The proportions of in-hospital mortality and 
the re-hospitalization rate as well as the additional outcomes were compared between groups using Pearson's Chi-squared test for count data. The associated effect estimates (mean differences and odds ratios) are given together with their associated $95 \%$ confidence interval. Mean differences and odds ratios were adjusted for gender and age category (in 5 year increments).

\section{Results}

In analysis 1 (Table 1), we compared 26,616 episodes of AECOPD during influenza seasons with 42,442 episodes of AECOPD outside of influenza seasons.

For hospitalisations with AECOPD during the influenza season, the LOS was significantly shorter (11.3 vs. 11.6 day, $p<0.001)$, there was no significant difference in terms of inhospital mortality ( 5.6 vs. $5.4 \%, p=0.751$ ), and the risk of being re-hospitalized for AECOPD was higher (33 vs. $31 \%$, $p<0.001$ ), while there was no significant difference in the occurrence of aspergillosis ( 0.1 vs. $0.2 \%, p=0.289)$.
In analysis 2 (Table 2), we compared 1004 AECOPD episodes with laboratory-confirmed influenza infection with 67,688 AECOPD episodes without laboratory-confirmed influenza.

For patients with AECOPD and lab-confirmed influenza, LOS (10.9 vs. 11.5 days, $p=0.083$ ) and risk for aspergillosis ( 0.2 vs. $0.2 \%, p=0.998)$ were not different, but in-hospital mortality (3.3 vs. $5.5 \%, p=0.010$ ) as well as re-hospitalization rate for AECOPD (29 vs. 37\%, $p<0.001)$ were lower.

In analysis 3 (Table 3), we compared among COPD patients, 734 episodes with pneumonia and confirmed influenza with 29,971 episodes with pneumonia without influenza diagnosis.

For COPD patients with a pneumonia episode with and without influenza, LOS (14.5 vs. 13.9 days, $p=0.226$ ), in-hospital mortality (7.4 vs. 8.6\%, $p=0.679$ ), re-hospitalization rate for AECOPD (34 vs. 34\%, $p=0.999$ ) risk of aspergillosis (0.8 vs. $0.4 \%, p=0.322)$ and empyema (0.7 vs. $0.9 \%, p=0.815)$ were not significantly different.
Table 1 Clinical outcomes of patients with AECOPD hospitalized during and outside influenza season

\begin{tabular}{|c|c|c|c|c|}
\hline Variable & $\begin{array}{l}\text { AECOPD during } \\
\text { influenza season }\end{array}$ & $\begin{array}{l}\text { AECOPD } \\
\text { outside influenza } \\
\text { season }\end{array}$ & OR/MD & $p$ \\
\hline Cases, $n$ & 26,616 & 42,442 & & \\
\hline Age distribution & $n(\%)$ & $n(\%)$ & & $<0.001$ \\
\hline 40-44 years & $131(0.5)$ & $285(0.7)$ & & \\
\hline $45-49$ years & $433(1.6)$ & $711(1.7)$ & & \\
\hline $50-54$ years & $868(3.3)$ & $1512(3.6)$ & & \\
\hline $55-59$ years & $1666(6.3)$ & $2831(6.7)$ & & \\
\hline $60-64$ years & $2619(9.8)$ & $4219(9.9)$ & & \\
\hline $65-69$ years & $3823(14.4)$ & $6098(14.4)$ & & \\
\hline $70-74$ years & $4592(17.3)$ & $7619(18.0)$ & & \\
\hline $75-79$ years & $4700(17.7)$ & $7347(17.3)$ & & \\
\hline $80-84$ years & $4242(15.9)$ & $6588(15.5)$ & & \\
\hline $85-89$ years & $2586(9.7)$ & $3827(9.0)$ & & \\
\hline 90-94 years & $819(3.1)$ & $1247(2.9)$ & & \\
\hline $95+$ years & $137(0.5)$ & $158(0.4)$ & & \\
\hline Female, $\%$ & 46 & 45 & $\begin{array}{l}\text { OR: } 1.02 \\
(95 \% \text { CI } 0.99-1.05)\end{array}$ & 0.209 \\
\hline \multicolumn{5}{|l|}{ Outcomes } \\
\hline Mean LOS, days & 11.3 & 11.6 & $\begin{array}{l}\text { Adj. MD: }-0.31 \\
(95 \% \text { CI: }-0.48 \text { to }-0.14)\end{array}$ & $<0.001$ \\
\hline In-hospital mortality, $\%$ & 5.6 & 5.4 & $\begin{array}{l}\text { Adj. OR: } 1.03 \\
(95 \% \text { CI } 0.96-1.10)\end{array}$ & 0.751 \\
\hline Risk of re-hospitalization, $\%$ & 33 & 31 & $\begin{array}{l}\text { Adj. OR: } 1.13 \\
\text { (95\% CI } 1.10-1.17)\end{array}$ & $<0.001$ \\
\hline Aspergillosis, \% & 0.1 & 0.2 & $\begin{array}{l}\text { Adj. OR } 0.72 \\
(95 \% \text { CI } 0.49-1.07)\end{array}$ & 0.289 \\
\hline
\end{tabular}

$O R$ odds ratio; $M D$ mean difference; $p p$ value; $C I$ confidence interval 
Table 2 Clinical outcomes of patients with AECOPD with and without confirmed influenza diagnosis

\begin{tabular}{|c|c|c|c|c|}
\hline Variable & $\begin{array}{l}\text { AECOPD with } \\
\text { influenza }\end{array}$ & $\begin{array}{l}\text { AECOPD with- } \\
\text { out influenza }\end{array}$ & $\mathrm{OR} / \mathrm{MD}$ & $p$ \\
\hline Cases, $n$ & 1004 & 67,688 & & \\
\hline Age distribution & $n(\%)$ & $n(\%)$ & & 0.859 \\
\hline $40-44$ years & $6(0.6)$ & $408(0.6)$ & & \\
\hline $45-49$ years & $20(2.0)$ & $1120(1.7)$ & & \\
\hline $50-54$ years & $38(3.8)$ & $2328(3.4)$ & & \\
\hline $55-59$ years & $61(6.1)$ & $4415(6.5)$ & & \\
\hline $60-64$ years & $97(9.7)$ & $6703(9.9)$ & & \\
\hline $65-69$ years & $145(14.4)$ & $9723(14.4)$ & & \\
\hline $70-74$ years & $197(19.6)$ & $11,954(17.7)$ & & \\
\hline $75-79$ years & $171(17.0)$ & $11,809(17.4)$ & & \\
\hline $80-84$ years & $159(15.8)$ & $10,613(15.7)$ & & \\
\hline $85-89$ years & $81(8.1)$ & $6297(9.3)$ & & \\
\hline 90-94 years & $26(2.6)$ & $2028(3.0)$ & & \\
\hline $95+$ years & $3(0.3)$ & $290(0.4)$ & & \\
\hline Female, $\%$ & 46 & 45 & $\begin{array}{l}\text { OR: } 1.05 \\
(95 \% \text { CI } 0.93-1.19)\end{array}$ & 0.443 \\
\hline \multicolumn{5}{|l|}{ Outcomes } \\
\hline Mean LOS, days & 10.9 & 11.5 & $\begin{array}{l}\text { Adj. MD: }-0.61 \\
(95 \% \mathrm{CI}-1.29 \text { to } 0.08)\end{array}$ & 0.083 \\
\hline In-hospital mortality, $\%$ & 3.3 & 5.5 & $\begin{array}{l}\text { Adj. OR: } 0.59 \\
(95 \% \text { CI } 0.42-0.84)\end{array}$ & 0.01 \\
\hline Risk of re-hospitalization, $\%$ & 29 & 37 & $\begin{array}{l}\text { Adj. OR: } 0.71 \\
(95 \% \text { CI } 0.62-0.89)\end{array}$ & $<0.001$ \\
\hline Aspergillosis, $\%$ & 0.2 & 0.2 & $\begin{array}{l}\text { Adj. OR: } 1.13 \\
\text { (95\% CI } 0.28-4.58)\end{array}$ & 0.998 \\
\hline
\end{tabular}

$O R$ odds ratio; $M D$ mean difference; $p p$ value; $C I$ confidence interval

\section{Discussion}

Our study, which analyzed all nation-wide AECOPD hospitalisations from 2012 to 2017 using three separate analyses, resulted in three main findings: First, AECOPD during influenza seasons did not have worse outcomes than outside influenza seasons, with shorter LOS but similar mortality and only slightly increased risk of re-hospitalization. Second, outcome was better if influenza was detected during hospitalization for AECOPD than if not, with lower mortality and risk of rehospitalisation at similar LOS. Third, in COPD patients with pneumonia, influenza diagnosis was associated with no significant difference in any outcome. Complications in form of aspergillosis were rare and not higher in any of our sub-groups. Overall, based on these data, there is no evidence of harmful effects on the clinical outcome of AECOPD in Switzerland by likely or confirmed influenza diagnosis, which is important information regarding the current management including corticosteroids [23].

Clinicians in Swiss hospitals usually adhere to local guidelines or practices, typically based on recommendations of the Centers for Disease Control and Prevention or European Centre for Disease Prevention and Control to determine when and in what patients influenza testing should be done, what leads to the widespread use of PCR or antigen testing during influenza epidemic period [24]. In contrast, testing for influenza virus infection outside the influenza epidemic period in patients without major suspicion for influenza is rarely performed. As a result, AECOPD with influenza may be considerably underdiagnosed — especially outside influenza epidemic period - and subsequently erroneously diagnosed and coded as AECOPD without influenza infection. Because of their simplicity, relatively low costs and fast results, during influenza epidemic rapid influenza diagnostic tests (RIDTs) are still a widely used method for influenza testing [10, 25]. As RIDTs show a high specificity, but a lower sensitivity compared to real-time (RT)-PCR testing or the newer rapid molecular assays, many cases of influenza infections as triggers for AECOPD may have been missed as they were classified as (false) negative results [26]. For these reasons, we performed separate analyses.

The first analysis comparing AECOPD during vs. outside the influenza season likely included most influenza episodes, but was not very specific_-rather a sensitivity analysis—as 
Table 3 Clinical outcomes in COPD patients of episodes of pneumonia with and without influenza diagnosis

\begin{tabular}{|c|c|c|c|c|}
\hline Variable & $\begin{array}{l}\text { Pneumonia with influenza in } \\
\text { patients with COPD }\end{array}$ & $\begin{array}{l}\text { Pneumonia without influenza } \\
\text { in patients with COPD }\end{array}$ & $\mathrm{OR} / \mathrm{MD}$ & $p$ \\
\hline Cases, $n$ & 734 & 29,971 & & \\
\hline Age distribution & $n(\%)$ & $n(\%)$ & & 0.015 \\
\hline 40-44 years & $4(0.5)$ & $142(0.5)$ & & \\
\hline $45-49$ years & $19(2.6)$ & $396(1.3)$ & & \\
\hline $50-54$ years & $25(3.4)$ & $770(2.6)$ & & \\
\hline $55-59$ years & $38(5.2)$ & $1494(5.0)$ & & \\
\hline $60-64$ years & $69(9.4)$ & $2554(8.5)$ & & \\
\hline $65-69$ years & $100(13.6)$ & 4027 (13.4) & & \\
\hline 70-74 years & $139(18.9)$ & $5168(17.2)$ & & \\
\hline $75-79$ years & $120(16.3)$ & $5567(18.6)$ & & \\
\hline $80-84$ years & $107(14.6)$ & $5147(17.2)$ & & \\
\hline $85-89$ years & $68(9.3)$ & $3338(11.1)$ & & \\
\hline 90-94 years & $40(5.4)$ & $1183(3.9)$ & & \\
\hline $95+$ years & $5(0.7)$ & $185(0.6)$ & & \\
\hline Female, $\%$ & 39 & 36 & OR: 1.11 (95\% CI 0.95-1.29) & 0.206 \\
\hline \multicolumn{5}{|l|}{ Outcomes } \\
\hline Mean LOS, days & 14.5 & 13.9 & $\begin{array}{l}\text { Adj. MD: } 0.65 \\
\text { (95\% CI: }-0.41 \text { to } 1.71)\end{array}$ & 0.226 \\
\hline In-hospital mortality, $\%$ & 7.4 & 8.6 & $\begin{array}{l}\text { Adj. OR: } 0.86 \\
\text { (95\% CI 0.65-1.14) }\end{array}$ & 0.679 \\
\hline Risk of re-hospitalization, $\%$ & 34 & 34 & $\begin{array}{l}\text { Adj. OR: } 1.00 \\
(95 \% \text { CI } 0.86-1.17)\end{array}$ & 0.999 \\
\hline Aspergillosis, $\%$ & 0.8 & 0.4 & $\begin{array}{l}\text { Adj. OR: } 1.94 \\
(95 \% \text { CI } 0.85-4.42)\end{array}$ & 0.322 \\
\hline Empyema, \% & 0.7 & 0.9 & $\begin{array}{l}\text { Adj. OR: } 0.69 \\
\text { (95\% CI } 0.28-1.68)\end{array}$ & 0.815 \\
\hline
\end{tabular}

$O R$ odds ratio; $M D$ mean difference; $p p$ value; $C I$ confidence interval

there still are many other infectious and non-infectious causes for exacerbation even during influenza periods, particularly for patients vaccinated against influenza. This analysis showed discordant results with no difference in inhospital mortality, a significantly shorter LOS but slightly higher risk of rehospitalisation for patients admitted during influenza season. An increased awareness for respiratory symptoms of COPD patients during influenza season might have led to lower threshold for hospitalization in case of suspicion for influenza-caused exacerbation and, therefore, quicker initiation of appropriate treatment including antivirals with faster clinical response [27]. Unfortunately, we did not have access to medication data. This might also explain the significantly higher rate of re-hospitalisations for AECOPD during influenza periods. The hypothesis of lower hospitalization threshold and, therefore, better outcomes during influenza season mirrors the results of a study on asthmatic and non-asthmatic patients with influenza, where earlier hospital admission and the early use of corticosteroids-both associated with asthmatics-were found as an explanation for better outcomes compared to hospitalized non-asthmatics [19]. Earlier hospitalization together with generally higher hospital occupancy during winter and spring results in greater pressure to discharge patients, and might have been at least partially responsible for the observed shorter mean LOS during influenza periods.

In contrast, comparing outcomes for AECOPD in patients with versus without influenza diagnosis in the second analysis would be most specific for influenza but likely misses many episodes caused by influenza [28]. There was no significant difference in terms of LOS, while in-hospital mortality and re-hospitalization rates were significantly lower in patients with influenza. This supports the notion that corticosteroids, which we assume were also given in AECOPD with influenza coinfection, did not worsen the outcome of those exacerbations, in contrast to their negative impact as adjunctive treatment in influenza alone [13, 29]. Consistent with this, we recently showed that COPD patients had less pneumonia-related complications, which possibly may be due to their use of inhaled corticosteroids [30]. These 
results confirm previous data from Korea and Hong Kong, that severity and outcomes were similar between AECOPD with or without viral detection [31, 32]. In contrast, older data suggested that there was a larger drop in peak flow and a longer recovery time in patients with viral AECOPD [27]. This might be confounded by the observation that viral exacerbations were more frequent in patients with higher GOLD stages [33]. A recent Canadian study showed that among 4755 patients with COPD hospitalized during influenza seasons, those with influenza diagnosis had significantly higher rates of mechanical ventilation, ICU admission, and mortality than influenza test-negative patients [34]. A further possible explanation for the result might be that hospitals with better standard of care are more consequent at influenza testing.

Finally, the special situation of COPD patients with a pneumonia episode - for which there is a German guideline recommendation - was analyzed by comparing outcomes between those with influenza diagnosis and those without [18]. Here, we did not find significant differences in any of the outcomes, which supports the current recommendation for corticosteroids in these patients. Of note is the low number of cases in the influenza test-positive group (734 hospitalisations with influenza vs. 29,971 without in 5 years). We assume that there is a substantial underdiagnosis of influenza-positive cases, which weakens the significance of this analysis. Still, our first two analyses point into the same direction. Furthermore, no significant differences between those groups in terms of complications such as aspergillosis or empyema were detected, which is also reassuring.

In general, our study did not find consistent evidence of a worse outcome in patients with AECOPD and any of our surrogates of influenza infection (epidemic period, laboratory-confirmed diagnosis) compared to patients without those surrogates. In all three analyses, there was only one outcome-risk of re-hospitalization-in analysis 1, which was worse in the presumed influenza group, while other parameters and most importantly mortality were either not different or in favor of the presumed influenza group.

Unfortunately, we did not have access to medication data to ultimately prove our associations. Still, we can assume that Swiss patients with AECOPD generally and in accordance with the 2020 GOLD report and current recommendations are treated with corticosteroids, irrespective of a possible or confirmed diagnosis of influenza [35] for the following reasons. First, the generally good adherence to guidelines in management of AECOPD. Second, in case of suspected AECOPD, corticosteroid treatment is usually initiated empirically and shortly after hospital admission, while the result of influenza testing, if performed at all, is usually not available yet. Third, an influenza diagnosis was confirmed in only a minority of likely influenza-associated
AECOPD episodes, which only would have possibly raised the concern about withholding corticosteroids.

Using an administrative database, it is impossible to exclude that a few patients may have been only subsequently coded as AECOPD and, therefore, may not have initially received corticosteroids. However, we do not consider this frequent enough of an event to have distorted our results.

Therefore, our data rather support the safety of corticosteroids in the majority of patients with AECOPD including those due to influenza. Even though influenza virus replication is increased in the presence of corticosteroids [36] and was shown in a recent meta-analysis to result in higher mortality and more nosocomial infections in influenza-associated severe pneumonia and acute-respiratory distress syndrome [37], these effects were not present in the population of patients with COPD in our study. Indeed, a recent meta-analysis of corticosteroids for ARDS indicated a survival benefit for ARDS of any etiology [38]. As possible explanation, we hypothesize that chronically obstructed lungs react differently and the major clinical determinants in this situation are rather the obstruction and inflammation [39], which are reduced with corticosteroids, rather than the viral cytopathic effect of influenza, which would be exacerbated by corticosteroids. However, the exact reasons for these observed differences between patients with and without COPD are not well understood.

\section{Limitations}

While the retrospective nation-wide study design allowed to analyze a large number of hospitalisations, it has limitations as all retrospective studies including detection bias. Using coding data, our study is dependent on coding quality. Coding errors might have resulted in erroneous inclusions or exclusions of hospitalisations. Nevertheless, to code and bill a diagnosis, a criterion of related work-up or clinical evidence has to be present, and as coding of hospitalization data became revenue-relevant for the stationary healthcare service providers in Switzerland in 2012, it is performed by professional coders ensuring high coding quality. Still, as a result of being a fairly young domain, coding may still be in a process of consolidation and have undergone slight changes throughout the period of our study. Another weakness of our study was the lack of baseline characteristics (e.g., details regarding means of COPD diagnosis or distinction from alternative diagnoses such as asthma, exact age, severity of disease or smoking or influenza vaccination status), which are not available in the dataset. For this reason, we could only adjust our analyses for gender and age category (in 5 year increments). As the analysis was restricted to hospitalized patients, we cannot generalize our findings to ambulatory patients. 
The main weakness is the lack of medication data in the database. With this, we can only make assumptions on how frequently corticosteroids as well as other medication (e.g., oseltamivir) are used in AECOPD in general and in particular when influenza is diagnosed or suspected. Nevertheless, as for hospitalized patients with AECOPD, the use of systemic steroids is standard of care in Switzerland and we are confident that most patients received them.

The main strength of this study is the size of the dataset which includes data from all hospitalisations in Switzerland and provided more than 8 million entries of hospitalisations from 2012 to 2017, thereby avoiding selection bias. This made it possible - in contrast to other study designs, which extrapolate from a random sample to the entire populationto accurately assess the total amount of hospitalization cases in Switzerland. This resulted in more than 30,000 cases for the smallest analysis and almost 70,000 for the bigger ones, what lies beyond most clinical trials and supports the robustness of our observations.

\section{Conclusions}

Using different comparisons and indicators for influenza as a cause of AECOPD, this study did not find evidence of a worse outcome in patients with AECOPD due to influenza. Assuming that most patients with AECOPD received corticosteroids, as it is accepted standard of care throughout Switzerland, this study showed no evidence of harmful effects of the current practice of routine corticosteroid treatment in patients hospitalized with AECOPD, also in the setting of likely influenza. Nevertheless, due to the lack of explicit information about the administered medication, final confirmation can only be obtained through prospective and ideally randomized controlled trials.

Supplementary Information The online version contains supplementary material available at https://doi.org/10.1007/s15010-021-01743-1.

Acknowledgements We would like to thank the coding department at Kantonsspital St. Gallen for their support regarding the selection and use of the ICD-coded diagnoses.

Author contributions SS and WA wrote the main manuscript text and prepared the figures. FB carried out the statistical calculations and analyzes. FR, FW, and MB added valuable inputs and improvements to the manuscript. All authors have contributed substantially to this manuscript, have read and agreed with the submitted version, and have no potential conflicts of interest to disclose.

Funding Not applicable (no funding).

Data availability The data that support the findings of this study are available from the Swiss Federal Statistical Office, but restrictions apply to the availability of these data, which were used under license for the current study, and so are not publicly available. Data are, however, available from the authors upon reasonable request and with permission of the Swiss Federal Statistical Office.

Code availability Statistical analyses have been executed with R (programming language), using ICD-10 codes as specified in the supplementary material.

\section{Declarations}

Conflict of interest On behalf of all authors, the corresponding author states that there is no conflict of interest.

Ethical approval An approval by an ethics committee was not applicable. See next paragraph for more detailed information on the topic.

Consent to participate The hospitalization database used in this analysis was provided by the Swiss Federal Statistical Office, which is the highest Swiss national agency. They do not require users of the database to seek informed consent, as patient information is fully anonymized and patients are unidentifiable, what makes it impossible to obtain consent. The database is available only upon reasonable request for research purposes.

\section{References}

1. Soriano JB, Abajobir AA, Abate KH, Abera SF, Agrawal A, Ahmed MB, et al. Global, regional, and national deaths, prevalence, disability-adjusted life years, and years lived with disability for chronic obstructive pulmonary disease and asthma, 1990-2015: a systematic analysis for the global burden of disease study 2015. Lancet Respir Med. 2017;5:691-706. https://doi.org/ 10.1016/S2213-2600(17)30293-X (Internet).

2. Hoyert DL, Xu J. Deaths: preliminary data for 2011. Natl Vital Stat Rep [Internet]. 2012;61:1-51. Available from: http://www. ncbi.nlm.nih.gov/pubmed/24984457. Accessed 27 Dec 2021

3. Lozano R, Naghavi M, Foreman K, Lim S, Shibuya K, Aboyans $\mathrm{V}$, et al. Global and regional mortality from 235 causes of death for 20 age groups in 1990 and 2010: a systematic analysis for the global burden of disease study 2010. Lancet. 2012;380:2095-128. https://doi.org/10.1016/S0140-6736(12)61728-0 (Internet).

4. Ray S, Guarascio, Finch ST. The clinical and economic burden of chronic obstructive pulmonary disease in the USA. Clin Outcomes Res. 2013;5:235. https://doi.org/10.2147/CEOR.S34321.

5. Buist AS, McBurnie MA, Vollmer WM, Gillespie S, Burney P, Mannino DM, et al. International variation in the prevalence of COPD (the bold study): a population-based prevalence study. Lancet. 2007;370:741-50.

6. Papi A, Bellettato CM, Braccioni F, Romagnoli M, Casolari P, Caramori G, et al. Infections and airway inflammation in chronic obstructive pulmonary disease severe exacerbations. Am J Respir Crit Care Med. 2006;173:1114-21. https://doi.org/10.1164/rccm. 200506-8590C (Internet).

7. Sethi S, Murphy TF. Infection in the pathogenesis and course of chronic obstructive pulmonary disease. N Engl J Med. 2008;359:2355-65. https://doi.org/10.1056/NEJMra0800353 (Internet).

8. Rohde G. Respiratory viruses in exacerbations of chronic obstructive pulmonary disease requiring hospitalization: a case-control study. Thorax. 2003;58:37-42. https://doi.org/10.1136/thorax. 58.1.37.

9. Centers for Disease Control and Prevention. Guide for considering influenza testing when influenza viruses are circulating in the 
community [Internet]. 2019 [cited 5 Oct 2021]. Available from: https://www.cdc.gov/flu/professionals/diagnosis/consider-influ enza-testing.htm

10. Influenza (Saisonale Grippe) » Guidelines.ch [Internet]. [cited 5 Oct 2021]. Available from: https://kssg.guidelines.ch/guideline/ $1727 / 6355$

11. COPD Global Initiative. 2020 Report [Internet]. Glob. Initiat. Chronic Obstr. Lung Dis. 2020. Available from: https://goldcopd. org/gold-reports/. Accessed 27 Dec 2021

12. Walters JA, Tan DJ, White CJ, Gibson PG, Wood-Baker R, Walters EH. Systemic corticosteroids for acute exacerbations of chronic obstructive pulmonary disease. Cochrane Database Syst Rev. 2014. https://doi.org/10.1002/14651858.CD001288.pub4 (Internet).

13. Rodrigo C, Leonardi-Bee J, Nguyen-Van-Tam J, Lim WS. Corticosteroids as adjunctive therapy in the treatment of influenza. Cochrane Database Syst Rev. 2016. https://doi.org/10.1002/14651 858.CD010406.pub2.

14. Siemieniuk RAC, Meade MO, Alonso-Coello P, Briel M, Evaniew $\mathrm{N}$, Prasad M, et al. Corticosteroid therapy for patients hospitalized with community-acquired pneumonia. Ann Intern Med. 2015;163:519-28. https://doi.org/10.7326/M15-0715 (Internet).

15. Briel M, Spoorenberg SMC, Snijders D, Torres A, Fernandez-Serrano S, Meduri GU, et al. Corticosteroids in patients hospitalized with community-acquired pneumonia: systematic review and individual patient data metaanalysis. Clin Infect Dis. 2018;66:346-54. https://doi.org/10.1093/cid/cix801 (Internet).

16. Metlay JP, Waterer GW, Long AC, Anzueto A, Brozek J, Crothers K, et al. Diagnosis and treatment of adults with communityacquired pneumonia. An official clinical practice guideline of the American thoracic society and infectious diseases society of America. Am J Respir Crit Care Med. 2019;200:45-67. https:// doi.org/10.1164/rccm.201908-1581ST (Internet).

17. Blum CA, Nigro N, Briel M, Schuetz P, Ullmer E, Suter-Widmer I, et al. Adjunct prednisone therapy for patients with communityacquired pneumonia: a multicentre, double-blind, randomised, placebo-controlled trial. Lancet [Internet]. 2015;385:1511-8. Available from: https://linkinghub.elsevier.com/retrieve/pii/S0140 673614624478. Accessed 27 Dec 2021

18. Ewig S, Kolditz M, Pletz M, Altiner A, Albrich W, Drömann D, et al. Behandlung von erwachsenen patienten mit ambulant erworbener pneumonie - update 2021. Pneumologie. 2021;75:665-729. https://doi.org/10.1055/a-1497-0693 (Internet).

19. Myles P, Nguyen-Van-Tam JS, Semple MG, Brett SJ, Bannister B, Read RC, et al. Differences between asthmatics and nonasthmatics hospitalized with influenza A infection. Eur Respir J. 2013;41:824-31. https://doi.org/10.1183/09031936.00015512 (Internet)

20. Bundesamt für Statistik. Medizinische Statistik der Krankenhäuser [Internet]. [cited 2021 Oct 5]. Available from: https://www.bfs. admin.ch/bfs/de/home/statistiken/gesundheit/erhebungen/ms.html

21. Albrich WC, Rassouli F, Waldeck F, Berger C, Baty F. Influence of older age and other risk factors on pneumonia hospitalization in Switzerland in the pneumococcal vaccine era. Front Med. 2019;6:1-10. https://doi.org/10.3389/fmed.2019.00286/full (Internet).

22. Bundesamt für Gesundheit. Saisonale Grippe-Lagebericht Schweiz [Internet]. [cited 5 Oct 2021]. Available from: https:// www.bag.admin.ch/bag/de/home/krankheiten/ausbrueche-epide mien-pandemien/aktuelle-ausbrueche-epidemien/saisonale-gripp e---lagebericht-schweiz.html

23. Buess M, Schilter D, Schneider T, Maurer M, Borer H, Thurnheer $\mathrm{R}$, et al. Treatment of COPD exacerbation in Switzerland: results and recommendations of the European COPD audit. Respiration. 2017;94:355-65. https://doi.org/10.1159/000477911 (Internet).
24. Empfehlungen für die Prävention und die Versorgung der Infektionen durch das Grippevirus in den Spitälern der lateinischen Schweiz. Konferenz der ärztlichen Direktorinnen und Direktoren (DirMED) sowie der Pflegedirektorinnen und Direktoren (DirDSO) der lateinischen Schweiz; 2018.

25. Chartrand C, Leeflang MMG, Minion J, Brewer T, Pai M. Accuracy of rapid influenza diagnostic tests: a meta-analysis. Ann Intern Med. 2012;156:500-11.

26. Merckx J, Wali R, Schiller I, Caya C, Gore GC, Chartrand C, et al. Diagnostic accuracy of novel and traditional rapid tests for influenza infection compared with reverse transcriptase polymerase chain reaction. Ann Intern Med. 2017;167:394. https://doi.org/ 10.7326/M17-0848.

27. Seemungal T, Donaldson GC, Bhowmik A, Jeffries DJ, Wedzicha JA. Time course and recovery of exacerbations in patients with chronic obstructive pulmonary disease. Am J Respir Crit Care Med. 2000;161:1608-13. https://doi.org/10.1164/ajrccm.161.5. 9908022 (Internet).

28. Wedzicha JA. Role of viruses in exacerbations of chronic obstructive pulmonary disease. Proc Am Thorac Soc. 2004;1:115-20. https://doi.org/10.1513/pats.2306030 (Internet).

29. World Health Organization. Clinical management of human infection with avian influenza A ( H5N1) virus [Internet]. Clin. Manag. Hum. Infect. with avian Influ. A virus. 2007. Available from: https://www.who.int/influenza/resources/documents/Clini calManagement07.pdf. Accessed 27 Dec 2021

30. Dusemund F, Chronis J, Baty F, Albrich W, Brutsche M. The outcome of community-acquired pneumonia in patients with chronic lung disease - a case-control study. Swiss Med Wkly [Internet]. 2014;144:1-8. Available from: http://doi.emh.ch/smw.2014. 14013. Accessed 27 Dec 2021

31. Kwak HJ, Park DW, Kim JE, Park MK, Koo GW, Park TS, et al. Prevalence and risk factors of respiratory viral infections in exacerbations of chronic obstructive pulmonary disease. Tohoku J Exp Med [Internet]. Japan; 2016;240:131-9. Available from: https://www.jstage.jst.go.jp/article/tjem/240/2/240_131/_article. Accessed 27 Dec 2021

32. Ko FWS, Ip M, Chan PKS, Chan MCH, To K-W, Ng SSS, et al. Viral etiology of acute exacerbations of COPD in Hong Kong. Chest [Internet]. 2007;132:900-8. Available from: https://linki nghub.elsevier.com/retrieve/pii/S0012369215366563. Accessed 27 Dec 2021

33. McManus TE, Marley A-M, Baxter N, Christie SN, O’Neill HJ, Elborn JS, et al. Respiratory viral infection in exacerbations of COPD. Respir Med [Internet]. 2008;102:1575-80. Available from: https://linkinghub.elsevier.com/retrieve/pii/S095461110 8002072. Accessed 27 Dec 2021

34. Mulpuru S, Li L, Ye L, Hatchette T, Andrew MK, Ambrose A, et al. Effectiveness of influenza vaccination on hospitalizations and risk factors for severe outcomes in hospitalized patients with COPD. Chest [Internet]. United States; 2019;155:69-78. Available from: https://linkinghub.elsevier.com/retrieve/pii/S001236921 8327259. Accessed 27 Dec 2021

35. Viniol C, Vogelmeier CF. Exacerbations of COPD. Eur Respir Rev. 2018;27:170103. https://doi.org/10.1183/16000617.01032017 (Internet).

36. Lee N, Chan PKS, Hui DSC, Rainer TH, Wong E, Choi K-W, et al. Viral loads and duration of viral shedding in adult patients hospitalized with influenza. J Infect Dis. 2009;200:492-500. https:// doi.org/10.1086/600383 (The University of Chicago Press, Internet).

37. Zhou Y, Fu X, Liu X, Huang C, Tian G, Ding C, et al. Use of corticosteroids in influenza-associated acute respiratory distress syndrome and severe pneumonia: a systemic review and meta-analysis. Sci Rep [Internet]. Nature Publishing Group UK; 
2020;10:3044. Available from: https://pubmed.ncbi.nlm.nih.gov/ 32080223. Accessed 27 Dec 2021

38. Chaudhuri D, Sasaki K, Karkar A, Sharif S, Lewis K, Mammen MJ, et al. Corticosteroids in COVID-19 and non-COVID-19 ARDS: a systematic review and meta-analysis. Intensive Care Med. 2021;47:521-37. https://doi.org/10.1007/s00134-02106394-2 (Internet).
39. Yin T, Zhu Z, Mei Z, Feng J, Zhang W, He Y, et al. Analysis of viral infection and biomarkers in patients with acute exacerbation of chronic obstructive pulmonary disease. Clin Respir J. 2018;12:1228-39. https://doi.org/10.1111/crj.12656 (Internet). 